\title{
Sorghums of the Sudan: analysis of regional diversity and distribution
}

\author{
C. Grenier ${ }^{1}$, P.J. Bramel ${ }^{2}$, J.A. Dahlberg ${ }^{3}$, A. El-Ahmadi ${ }^{4}$, M. Mahmoud ${ }^{4}$, G.C. Peterson ${ }^{5}$, \\ D.T. Rosenow ${ }^{5}$ and G. Ejeta ${ }^{1, *}$ \\ ${ }^{1}$ Department of Agronomy, Purdue University, Lilly Hall, 47907, West Lafayette, IN, USA; ${ }^{2}$ ICRISAT, \\ Matopos Research Station, PO Box 776, Bulawayo, Zimbabwe; ${ }^{3}$ National Grain Sorghum Producers, P.O. \\ Box 5309, Lubbock, TX 79408, USA; ${ }^{4}$ Agricultural Research Corporation, Gezira Research Station, Wad \\ Medani, Sudan; ${ }^{5}$ Agricultural Research and Extension Center, Texas A\&M University, Rt. 3, Box 219, \\ Lubbock, TX 79403-9757, USA; *Author for correspondence
}

Received 15 May 2002; accepted in revised form 11 January 2003

Key words: Sorghum bicolor, Germplasm, Phenotypic diversity, Principal component analysis, Shannon-Weaver index, Sudan

\begin{abstract}
Sorghum [Sorghum bicolor (L.) Moench] is a very important crop in the Sudan serving as a primary source of food, beverage, and total livelihood for millions of people in the country. The crop originated in the Northeast quadrant of Africa, and the Sudan is widely recognized as a major center of diversity. Although Sudanese sorghum germplasm has been assembled and stored over the last 50 years, careful analysis of this valuable germplasm has not been made. The objectives of this study were to assess phenotypic diversity and compare pattern of distribution among Sudanese sorghum landraces collected from different geographical regions. Phenotypic diversity among landraces was high, as expressed by the large range of variation for mean quantitative traits and the high $(0.81)$ Shannon-Weaver diversity index. Landraces from Gezira-Gedarif tended to be shorter in stature, earlier in maturity and less sensitive to changes in photoperiod. They also had long, narrow and compact panicles that may result from adaptation to low rainfall and early adoption of mechanized farming practices. In contrast, taller and later maturing plant types characterized sorghums from Equatoria, most of which delayed their flowering in response to increased day-length. These sorghums included many genotypes with small and light kernels. Collections from Kassala showed a higher frequency of landraces with kernels that were more difficult to thresh. Landraces from Blue Nile tended to have greater agronomic eliteness with higher proportion of landraces with white kernels, poorly covered and that were easy to thresh. Sorghums from the Upper Nile tended to have loose panicles with poorly covered kernels that may result from adaptation to high rainfall of the Southern region. Although distinct distributions of types were represented by geographical origin, a high level of within-region diversity was present among all Sudanese sorghums.
\end{abstract}

Sorghum originated in the Northeast quadrant of Africa over 3,000 years ago, and slowly dispersed into other parts of Africa eventually spreading into Asia and the rest of the world (Harlan and Stemler 1976; Mann et al. 1983). Diversity of sorghum appears to be highly correlated with duration of domestication and the type of farming practiced. High level of diversity was reported in sorghums from Ethiopia (Ayana and Bekele 1998, 1999, 2000), a primary center of origin, from India, a secondary center of domestication
(Appa Rao et al. 1996), as well as from China, another important center of diversity for sorghum ( $\mathrm{Li}$ and $\mathrm{Li}$ 1997). Ayana and Bekele evaluated phenotypic diversity on 415 sorghum landraces from Ethiopia and Eritrea and reported high phenotypic diversity along adaptation zones. Appa Rao and coworkers studied 2,343 Indian landraces from the sorghum ex-situ collection maintained at the International Crop Research Institute for the Semi-Arid Tropics (ICRISAT) and found higher phenotypic diversity among acces- 
sions from different states than those from within a state. Among 10,386 Chinese sorghum landraces kept at the national genebank in Beijing, Li and Li (1997) found a high degree of phenotypic diversity in the collection and reported the most diversity in landraces from regions with the longest history of sorghum cultivation.

Sudan is one of the most important centers of sorghum domestication and cultivation. Sorghum is grown in every region of the country where it is possible to raise a crop. Nearly $80 \%$ of the total grain production in the country is obtained from sorghum (FAO, 2001). It is the staff of life for all Sudanese. In many parts of the country the crop is wholly utilized (Ejeta 1980). The grain is used for making kisra (unleavened bread from fermented dough), a local porridge, asida, a non-alcoholic beverage, abreih, and a local beer, marisa. The stalks are used as building material and the straw is utilized as animal feed or as source of fuel. The great importance and the unique place that sorghum holds in the lives of all Sudanese was aptly described by Bacon (1948) who wrote, "... no where more so than in Sudan, where it provides food and drink for man and more sustenance for beast than all other cultivated crops together. Easy to grow, hardy to survive, readily cooked and brewed and keeping well in store, it is the nutritional backbone of the country."

Sorghums from the Sudan have impacted sorghum improvement efforts globally. They have served as germplasm sources for improvements in yield, drought tolerance, stalk strength, insect and disease resistance, as well as nutritional quality (Rosenow and Dahlberg 2000). Early introductions of sorghum into the USA were primarily from the Sudan. Sudan was probably the place where mutations for height and maturity took place in nature and where 'US-type sorghums' originated, providing excellent opportunity for gene transfer between tropical and temperate sorghums (Rao 1977). Indeed many varieties such as hegaris, feteritas, zera zeras and kurgis have contributed much towards breeding of improved sorghum varieties in both USA and India (Rao and Mengesha 1980). In spite of their immense global importance, however, no organized diversity analysis has been reported on sorghums of the Sudan except for a few collection reports describing apparent variability among landraces (Rao 1977; Rao and Mengesha 1980; Ejeta 1980). The value of these collections is better appreciated if a thorough analysis of the genetic diversity is undertaken. The objective of this study, therefore, is to assess regional phenotypic and genetic diversity estimates for a better understanding of the diversity and distribution of the present Sudanese sorghum collection and to provide a basis for formulating policy for future action.

\section{Material and Methods}

\section{Passport Information}

A total of 2,017 Sudanese sorghum landraces in the ICRISAT genebank were included for this study (Table 1). Passport information of accessions were designated either by scientists of the institute which transferred the material to ICRISAT, or by local farmers where the germplasm accession was collected. Accessions that are geo-referenced in the collection were from five provinces: Gezira-Gedarif (includes entries from El Gezira, Khartoum, and Gedarif), Kassala, Blue Nile, Upper Nile and Equatoria. Collections from Kordofan, a region of significant genetic diversity, were included in the "unknown source" category (Table 1), since the database lacks appropriate georeference for collections from this region. The collection was divided into three groups corresponding to the nature of the material, i.e., breeding lines, advanced selections (both originating from Sudanese research institutes), or landraces. Only landraces were considered in the present study. Landraces collected from farmers' fields were designated with local names as well as localities and geographical coordinates (latitude, longitude and altitude) of the sampled fields. Accessions from local markets or those donated by individuals were described for passport data with local names occasionally, but primarily by the contributing institutes' geographical location. Within each region, the collected landraces were assumed to be a random sample of the regional population of sorghum landraces.

\section{Characterization Data}

Upon entry into the genebank at ICRISAT, an international sorghum number (IS number) was assigned to each accession. Results from morphologic characterization and agronomic evaluation for each accession were recorded in the ICRISAT database. Morphologic characterization of accessions was conducted at ICRISAT over the last 20 years as described by Appa 
Table 1. Regional representation of Sudanese sorghum landraces in the ICRISAT genebank.

\begin{tabular}{ll}
\hline Region & No of entries \\
\hline Gezira-Gedarif & 752 \\
Kassala & 45 \\
Blue Nile & 73 \\
Upper Nile & 144 \\
Equatoria & 18 \\
Unknown Region* & 985 \\
Total landraces & 2017 \\
\hline
\end{tabular}

* includes accessions from Kordofan.

Rao et al. (1996). Unreplicated single row plots of these accessions were grown in a completely randomized design on a vertisol soil at ICRISAT Patancheru, India $\left(17^{\circ} 25^{\prime} \mathrm{N}, 78^{\circ} \mathrm{E}\right)$ and characterized during the rainy and the post-rainy seasons (Rao and Bramel 2000). Longer day-lengths, lower temperatures, and cloudy and rainy weather often characterize the rainy season. Only plant height (PHTK) and days to flowering (FLK) were recorded during the Kharif, long rainy season. During the Rabi, post-rainy season, data were recorded for seven quantitative characters, namely, plant height (PHTR), days to flowering (FLR), panicle exsertion (PEX), panicle length and width (PLG and PWD), kernel size (KRS), and 100seed weight (SWT). Additional data on one ordinal character, i.e. number of basal tillers (BT), and on 10 qualitative characters, namely presence of nodal tillers (NT), plant pigmentation (PIG), glume color (GLC), midrib color (MIC), panicle compactness and shape (PCS), threshability (THR), glume covering (COV), kernel color (KRC), endosperm texture (TEX), and presence of subcoat (SC) were also recorded. Race classification of Sorghum bicolor ssp. bicolor, as proposed by Harlan and de Wet (1972) and defined by five races (Bicolor, Caudatum, Durra, Guinea and Kafir) and their 10 intermediates based on spikelet and panicle shape at maturity, was used to assess racial distribution.

In a recent study (Grenier 2000), this phenotypic database was validated with a new set of data collected on 642 randomly selected accessions during both the Kharif and Rabi season of 1997 and 1998, at Patancheru, India. Experimental layout was again, single row plots, completely randomized, and with a local genotype interspersed as check. Phenotypic characterization was conducted to assess location and year effects. Results indicated that data on all quantitative characters were found highly and positively correlated with records found in the ICRISAT database.

\section{Statistical Analyses}

Basic descriptive statistics of range, mean, and standard error were computed on the nine quantitative traits for accessions from each region. Geographic distribution of diversity was assessed using mean and frequency comparisons. To reduce statistical error associated with small sample size, provinces with the fewest entries were grouped together into a larger region. Such was the case for two accessions from Khartoum, which were grouped with material from El Gezira and Gedarif to form the Gezira-Gedarif region. Regional means were compared through unequal variance $t$-tests as recommended for cases where assumption of homogeneity of variance is not met (Johnson 1995). Experiment-wise error was minimized by adjusting the critical probability for accepting differences to $\mathrm{p}<0.005(=\mathrm{p}<0.05 / \mathrm{n}$ where $\mathrm{n}=$ 10 pairwise tests) as per Bonferroni. Mean comparisons were performed using SAS version 8.2 (SAS Institute Inc., 2001).

Ten qualitative and one ordinal character were encoded with two to six classes. Frequency distributions for the 11 discrete variables were determined by grouping observations according to regional origin. For each region, deviation from the expected frequency, as obtained from the distribution in the total landrace collection minus the region under consideration, was assessed using a $\mathrm{Chi}^{2}$ test and applied according to procedure described by Snedecor and Cochran (1989). Comparisons were only performed when the expected frequency for a specific class was greater than unity. $\mathrm{Chi}^{2}$ test was not performed when this condition was not met.

Morphological diversity was also estimated by considering multiple characters together. Principal component analysis was performed on the nine quantitative characters after standardizing the data to a mean of zero and variance of one. Number of extracted factors was determined following the Kaiser criterion, and factors were only retained when their eigenvalue exceeded unity. Varimax rotation procedure was used to determine the factor load as it maximized the variance of the squared normalized factor loadings across variables for each factor. Principal component analysis was performed with the Statistica version 5.1 software (Statsoft 1997).

Shannon-Weaver index of diversity $\left(\mathrm{H}^{\prime}\right)$ was com- 
puted for each discrete character from frequency distributions observed in the different classes according to the following formula as demonstrated by Hutcheson (1970):

$$
H^{\prime}{ }_{C}=\sum_{i=1}^{n} p_{i} \log p_{i}
$$

where for a given character $C, n$ is the number of phenotypic classes and $p_{i}$ is the proportion of observation in the $i^{\text {th }}$ class. Due to its additive property, values for $H^{\prime}{ }_{C}$ were pooled over the characters, and global phenotypic diversity estimated by the mean index value. For each index obtained per region, $\mathrm{H}^{\prime}$ variance was calculated prior to comparing indices through $t$-tests as shown in Jain et al. (1975) with $t=$ $\left(\mathrm{H}^{\prime}{ }_{1}-\mathrm{H}^{\prime}{ }_{2}\right) /\left[\operatorname{var}\left(\mathrm{H}^{\prime}{ }_{1}\right)+\operatorname{var}\left(\mathrm{H}^{\prime}{ }_{2}\right)\right]^{1 / 2}$, at degrees of freedom $\left[\operatorname{var}\left(\mathrm{H}^{\prime}{ }_{1}\right)+\operatorname{var}\left(\mathrm{H}^{\prime}{ }_{2}\right)\right]^{2} /\left[\operatorname{var}\left(\mathrm{H}^{\prime}{ }_{1}\right)^{2} / \mathrm{N}_{1}+\right.$ $\left.\operatorname{var}\left(\mathrm{H}^{\prime}{ }_{2}\right)^{2} / \mathrm{N}_{2}\right]$, where $\mathrm{N}_{1}$ and $\mathrm{N}_{2}$ are the numbers of entries in the two groups. Type I error was minimized with the Bonferroni adjustment.

\section{Results}

\section{Passport Distribution}

Among the 2,017 Sudanese sorghum landraces maintained at ICRISAT, only $45 \%$ were geo-referenced in the database with information on province and/or specific locality of origin (Table 1). Gezira-Gedarif, one of the major irrigation schemes and large-scale mechanized sorghum farming areas of the world
(FAO, 2001), is home to $73 \%$ of the geo-referenced landraces. Among landraces collected on-farm, 52.5\% were from 20 different localities in the Blue Nile province. Upper Nile included fewer on-farm collections since all of the entries were designated as originating from Tozi, where an old rainland experiment station was located.

\section{Racial Distribution}

All the races except the Guinea-Kafir intermediate were present (Table 2) in the Sudan collection. Four landraces belonging to the subspecies $S$. bicolor $\mathrm{ssp}$. drummondii (an annual weedy species) were also present. Landraces belonging to the race Kafir, its intermediates Bicolor-Kafir and Durra-Kafir, and the intermediate Bicolor-Guinea were under-represented in the Sudan collection. Race distribution in the Sudan collection was heavily skewed $(80 \%)$ towards the Caudatum race and its intermediate forms.

Racial distribution was markedly different among regions. Sorghums from Gezira-Gedarif included 14 races made up mainly of Caudatum and its intermediate races. Among landraces from the Kassala region, six races were present with Caudatum and Durra equally represented. Race Bicolor represented $16 \%$ of the landraces from Kassala. This is much higher than the frequency of the Bicolor sorghums in the total Sudanese collection (4\%). In the Blue Nile region, six races of sorghum were included with race Caudatum predominating ( $49 \%$ ) followed by its intermediate Caudatum-Guinea $(27 \%)$. More races were included in landrace sorghums from Upper Nile

Table 2. Racial representation among Sudanese sorghum landraces across geographic regions of origin.

\begin{tabular}{|c|c|c|c|c|c|c|c|}
\hline Race & Gezira-Gedarif & Kassala & Blue Nile & Upper Nile & Equatoria & Unknown Region & Total \\
\hline Bicolor & 8 & 7 & 1 & 1 & 0 & 62 & 79 \\
\hline Caudatum & 292 & 12 & 36 & 101 & 10 & 438 & 889 \\
\hline Durra & 90 & 13 & 8 & 10 & 0 & 88 & 209 \\
\hline Guinea & 14 & 0 & 0 & 2 & 4 & 15 & 35 \\
\hline Kafir & 2 & 0 & 0 & 0 & 0 & 0 & 2 \\
\hline BC: Bicolor-Caudatum & 55 & 0 & 1 & 3 & 0 & 51 & 110 \\
\hline BD: Bicolor-Durra & 16 & 2 & 0 & 0 & 0 & 24 & 42 \\
\hline BG: Bicolor-Guinea & 3 & 0 & 0 & 0 & 0 & 4 & 7 \\
\hline BK: Bicolor-Kafir & 3 & 0 & 0 & 1 & 0 & 3 & 7 \\
\hline CD: Caudatum-Durra & 104 & 7 & 7 & 12 & 0 & 101 & 231 \\
\hline CG: Caudatum-Guinea & 129 & 4 & 20 & 13 & 4 & 172 & 342 \\
\hline CK: Caudatum-Kafir & 15 & 0 & 0 & 1 & 0 & 18 & 34 \\
\hline DG: Durra-Guinea & 19 & 0 & 0 & 0 & 0 & 5 & 24 \\
\hline DK: Durra-Kafir & 2 & 0 & 0 & 0 & 0 & 0 & 2 \\
\hline S. bicolor drummondii & 0 & 0 & 0 & 0 & 0 & 4 & 4 \\
\hline Total & 752 & 45 & 73 & 144 & 18 & 985 & 2017 \\
\hline
\end{tabular}


where, there too, $70 \%$ of the landraces were classified as Caudatum. The least diverse region, race-wise, was Equatoria, where only 10 Caudatum, four Guinea, and four Caudatum-Guinea landraces were reported.

\section{Phenotypic Distribution}

Descriptive statistics were computed for the total collection as well as for group of accessions based on area of origin to estimate the geographic partitioning of phenotypic diversity. To avoid redundancy and improve readability, the results of these analyses were presented by grouping related traits together under the general categories of quantitative and discrete characters. Univariate analyses conducted on each of the nine quantitative characters are presented in (Table 3 ), while results of descriptive statistics on the 11 discrete traits are presented in (Table 4).

\section{Quantitative characters}

Plant morphology and phenology: The shortest $($ PHTR $=85 \mathrm{~cm})$ and the earliest $($ FLR $=41$ days $)$ sorghums recorded during the post-rainy season were found among sorghums from Gezira-Gedarif, which also had the smallest lower limit of range values $\left(\mathrm{PHTR}_{\min }=85 \mathrm{~cm}\right.$ and $\mathrm{FLR}_{\text {min }}=41$ days $)$. Among accessions from the Blue Nile region were the tallest $($ PHTR $=350 \mathrm{~cm})$ and among the latest $($ FLR $=103$ days) sorghums. Accessions from the Upper Nile region were among the shortest and earliest sorghums with the smallest upper limit of range values for both height $\left(\right.$ PHTR $\left._{\max }=260 \mathrm{~cm}\right)$ and days to flowering $\left(\mathrm{FLR}_{\max }=82\right.$ days). The lowest limits in range of both PHTR and FLR values were the highest for sorghums from Equatoria $\left(\mathrm{PHTR}_{\min }=170 \mathrm{~cm}\right.$ and $\mathrm{FLR}_{\text {min }}=84$ days). Characters recorded during the

Table 3. Range, mean and standard error ( \pm S.E.) for nine quantitative characters of sorghum landraces collected from different regions of the Sudan.

\begin{tabular}{|c|c|c|c|c|c|c|c|}
\hline Character & Statistics & Gezira-Gedarif & Kassala & Blue Nile & Upper Nile & Equatoria & Total* \\
\hline & No of entries & 752 & 45 & 73 & 144 & 18 & 2017 \\
\hline \multirow[t]{3}{*}{ PHTR } & Range & $85-275$ & $140-330$ & $120-350$ & $115-260$ & $170-275$ & $70-390$ \\
\hline & Mean & $169.26^{\mathrm{a}}$ & $208.00^{\mathrm{b}}$ & $200.82^{\mathrm{b}}$ & $192.47^{\mathrm{b}}$ & $236.67^{c}$ & 189.77 \\
\hline & \pm S.E. & 1.16 & 5.74 & 6.52 & 2.57 & 6.81 & 1.09 \\
\hline \multirow[t]{3}{*}{ FLR } & Range & $41-92$ & $51-89$ & $54-103$ & $45-82$ & $84-106$ & $41-110$ \\
\hline & Mean & $62.10^{\mathrm{a}}$ & $68.11^{\mathrm{b}}$ & $72.12^{b}$ & $59.06^{\mathrm{c}}$ & $89.89^{d}$ & 66.78 \\
\hline & \pm S.E. & 0.25 & 1.06 & 1.38 & 0.56 & 1.41 & 0.26 \\
\hline \multirow[t]{3}{*}{ PHTK } & Range & $100-490$ & $155-440$ & $185-495$ & $135-440$ & $250-480$ & $85-615$ \\
\hline & Mean & $262.60^{\mathrm{a}}$ & $311.74^{\mathrm{b}}$ & $300.62^{\mathrm{b}}$ & $317.41^{\mathrm{bc}}$ & $371.67^{c}$ & 299.42 \\
\hline & \pm S.E. & 2.76 & 9.26 & 8.52 & 6.15 & 16.80 & 1.89 \\
\hline \multirow[t]{3}{*}{ FLK } & Range & $45-190$ & $58-115$ & $55-145$ & $50-150$ & $84-141$ & $45-190$ \\
\hline & Mean & $72.08^{\mathrm{a}}$ & $82.81^{\mathrm{b}}$ & $91.48^{b}$ & $84.36^{\mathrm{b}}$ & $112.72^{c}$ & 86.07 \\
\hline & \pm S.E. & 0.66 & 2.34 & 2.57 & 1.49 & 4.42 & 0.59 \\
\hline \multirow[t]{3}{*}{ PEX } & Range & $0-48$ & $0-31$ & $0-40$ & $0-32$ & $9-31$ & $0-48$ \\
\hline & Mean & $17.33^{\mathrm{ab}}$ & $14.56^{\mathrm{a}}$ & $14.67^{\mathrm{a}}$ & $15.49^{\mathrm{a}}$ & $22.39^{\mathrm{b}}$ & 17.35 \\
\hline & \pm S.E. & 0.29 & 1.30 & 1.03 & 0.60 & 1.66 & 0.20 \\
\hline \multirow[t]{3}{*}{ PLG } & Range & $7-37$ & $10-44$ & $15-33$ & $9-42$ & $13-32$ & $7-44$ \\
\hline & Mean & $21.13^{\mathrm{ab}}$ & $20.96^{\mathrm{ab}}$ & $21.96^{\mathrm{a}}$ & $19.85^{b}$ & $20.94^{\mathrm{ab}}$ & 21.60 \\
\hline & \pm S.E. & 0.17 & 0.95 & 0.43 & 0.42 & 1.34 & 0.12 \\
\hline \multirow[t]{3}{*}{ PWD } & Range & $3.5-25$ & $6-25$ & $6-25$ & $1-17$ & $5-12$ & $1-30$ \\
\hline & Mean & $7.46^{\mathrm{a}}$ & $10.18^{b}$ & $10.25^{b}$ & $6.64^{\mathrm{c}}$ & $7.50^{\mathrm{ac}}$ & 8.38 \\
\hline & \pm S.E. & 0.10 & 0.53 & 0.35 & 0.19 & 0.41 & 0.07 \\
\hline \multirow[t]{3}{*}{ KRS } & Range & $2-5$ & $1.8-5$ & $2-4$ & $2.5-5$ & $2.5-3$ & $1-5$ \\
\hline & Mean & $3.20^{\mathrm{a}}$ & $3.16^{\mathrm{ab}}$ & $2.98^{\mathrm{b}}$ & $3.85^{\mathrm{c}}$ & $2.74^{\mathrm{d}}$ & 3.23 \\
\hline & \pm S.E. & 0.02 & 0.08 & 0.04 & 0.04 & 0.03 & 0.01 \\
\hline \multirow[t]{3}{*}{ SWT } & Range & $1.32-6.92$ & $1.47-7.3$ & $2.36-6.2$ & $1.8-6.77$ & $1.94-3.4$ & $0.8-7.3$ \\
\hline & Mean & $3.53^{\mathrm{a}}$ & $3.68^{\mathrm{a}}$ & $3.44^{\mathrm{a}}$ & $3.66^{\mathrm{a}}$ & $2.84^{\mathrm{b}}$ & 3.48 \\
\hline & \pm S.E. & 0.03 & 0.19 & 0.09 & 0.07 & 0.10 & 0.02 \\
\hline
\end{tabular}

PHTR: plant height recorded during the Rabi season $(\mathrm{cm})$, FLR: days to flowering recorded during the Rabi season, PHTK: plant height recorded during the Kharif season $(\mathrm{cm})$, FLK: days to flowering recorded during the Kharif season, PEX: panicle exsertion (cm), PLG: panicle length $(\mathrm{cm})$, PWD: panicle width $(\mathrm{cm})$, KRS: kernel size $(\mathrm{mm})$, SWT: 100-seed weight $(\mathrm{g})$. Unequal variance t-tests with Bonferroni adjustment; means in a row followed by the same letter are not significantly different at $\mathrm{p}<0.005$ (comparison-wise Type I error rate).

* includes the unknown sources. 
Table 4. Distribution of landraces for each class of 11 discrete characters of sorghum landraces collected from different regions of the Sudan

\begin{tabular}{|c|c|c|c|c|c|c|c|c|}
\hline Character & Class & Gezira-Gedarif & Kassala & Blue Nile & Upper Nile & Equatoria & Unknown Region ${ }^{n t}$ & Total \\
\hline \multirow[t]{3}{*}{ BT } & 1 tiller & $0.58 *$ & $0 *$ & $0^{*}$ & 0.25 & 0.44 & 0.14 & 0.30 \\
\hline & 2 tillers & $0.31 *$ & $0.78^{*}$ & $0.78 *$ & $0.62 *$ & 0.50 & 0.43 & 0.42 \\
\hline & $\geq 3$ tillers & $0.11^{*}$ & 0.22 & 0.22 & $0.13^{*}$ & 0.06 & 0.43 & 0.28 \\
\hline \multirow[t]{2}{*}{ NT } & absence & $0.05^{*}$ & 0 & $0.01 *$ & $0.16^{*}$ & $0.89^{*}$ & 0.08 & 0.08 \\
\hline & presence & 0.95 & 1.00 & 0.99 & 0.84 & $0.11 *$ & 0.92 & 0.92 \\
\hline \multirow[t]{2}{*}{ PIG } & pigmented & 0.94 & 1.00 & 0.90 & 0.91 & 1.00 & 0.92 & 0.93 \\
\hline & $\tan$ & 0.06 & 0 & 0.10 & 0.09 & 0 & 0.08 & 0.07 \\
\hline \multirow[t]{4}{*}{ GLC } & black/purple & 0.53 & 0.38 & 0.41 & 0.60 & 0.56 & 0.54 & 0.53 \\
\hline & red & $0.11 *$ & 0.11 & 0.19 & 0.15 & 0.33 & 0.19 & 0.16 \\
\hline & sienna & $0.24 *$ & $0.33 *$ & $0.37 *$ & $0.06 *$ & 0.06 & 0.16 & 0.19 \\
\hline & mahogany & 0.13 & 0.18 & $0.03 *$ & $0.20 *$ & 0.06 & 0.10 & 0.12 \\
\hline \multirow[t]{3}{*}{ MIC } & dull & 0.34 & 0.20 & $0.62 *$ & 0.37 & 0.33 & 0.37 & 0.36 \\
\hline & white & $0.66^{*}$ & 0.51 & $0.34 *$ & 0.63 & 0.56 & 0.62 & 0.62 \\
\hline & yellow & $\cong 0.00^{*}$ & $0.29^{n t}$ & 0.04 & 0.01 & $0.06^{n t}$ & 0.01 & 0.02 \\
\hline \multirow[t]{3}{*}{ PCS } & compact & $0.69^{*}$ & 0.60 & 0.60 & $0.69^{*}$ & 0.28 & 0.45 & 0.56 \\
\hline & loose stiff & $0.31 *$ & 0.38 & 0.38 & $0.17 *$ & 0.50 & 0.51 & 0.40 \\
\hline & loose drooping & $0.01 *$ & 0.02 & 0.01 & $0.14 *$ & $0.22^{n t}$ & 0.04 & 0.03 \\
\hline \multirow[t]{3}{*}{ THR } & easy & $0.62 *$ & 0.78 & $0.97 *$ & $0.26^{*}$ & 1.00 & 0.75 & 0.68 \\
\hline & partly & $0.36^{*}$ & $0.02 *$ & $0 *$ & $0.72 *$ & $0^{*}$ & 0.17 & 0.27 \\
\hline & difficult & $0.03^{*}$ & $0.20 *$ & 0.03 & 0.02 & 0 & 0.08 & 0.06 \\
\hline \multirow[t]{3}{*}{$\mathrm{COV}$} & $\leq 25 \%$ & $0.42 *$ & 0.40 & $0.70 *$ & $0.60 *$ & 0.61 & 0.49 & 0.48 \\
\hline & $50 \%$ & $0.47^{*}$ & 0.40 & 0.27 & 0.37 & 0.39 & 0.36 & 0.40 \\
\hline & $\geq 75 \%$ & 0.11 & 0.20 & $0.03^{*}$ & $0.03^{*}$ & 0 & 0.15 & 0.12 \\
\hline \multirow[t]{6}{*}{$\mathrm{KRC}$} & straw & $0.21 *$ & 0.07 & 0.12 & 0.12 & 0.06 & 0.12 & 0.15 \\
\hline & yellow & $0.07 *$ & 0.09 & 0.04 & 0.04 & $0^{n t}$ & 0.04 & 0.05 \\
\hline & white & $0.17^{*}$ & 0.09 & $0.25^{*}$ & $0.03 *$ & 0.06 & 0.08 & 0.11 \\
\hline & brown & $0.21 *$ & 0.20 & 0.25 & 0.31 & $0.56^{*}$ & 0.34 & 0.28 \\
\hline & grey & $0.21 *$ & 0.38 & 0.30 & $0.35^{*}$ & 0.11 & 0.30 & 0.27 \\
\hline & red & 0.13 & 0.18 & $0.04 *$ & 0.15 & 0.22 & 0.13 & 0.13 \\
\hline \multirow[t]{3}{*}{ TEX } & mostly corneous & $0.09^{*}$ & 0.04 & 0.03 & 0.04 & 0 & 0.06 & 0.06 \\
\hline & partly corneous & $0.46^{*}$ & 0.40 & 0.37 & $0.28 *$ & 0.44 & 0.36 & 0.40 \\
\hline & partly starchy & $0.45^{*}$ & 0.56 & 0.60 & $0.67 *$ & 0.56 & 0.58 & 0.54 \\
\hline \multirow[t]{2}{*}{$\mathrm{SC}$} & presence & $0.42 *$ & 0.53 & 0.58 & $0.74 *$ & 0.61 & 0.71 & 0.60 \\
\hline & absence & $0.58^{*}$ & 0.47 & 0.42 & $0.26^{*}$ & 0.39 & 0.29 & 0.40 \\
\hline
\end{tabular}

BT: number of basal tillers, NT: nodal tillers, PIG: plant pigmentation, GLC: glume color, MIC: midrib color, PCS: panicle compactness and shape, THR: threshability, COV: glume covering, KRC: kernel color, TEX: endosperm texture, SC: subcoat. Frequencies for each region are compared to the expected ones found in the total collection minus the region under consideration through a $\mathrm{Chi}^{2}$ test; ${ }^{n t}$ indicates that frequency were not tested for deviation from the expected frequency; $*$ indicates significant differences at $\mathrm{p}<0.05$.

rainy season reflect adaptation to longer day-lengths. The ranking of regions for PHTK showed the same pattern as for PHTR with significant $(\mathrm{p}<0.05)$ correlation between PHTR and PHTK and with high coefficient among regions $(\operatorname{Pr}=0.64)$. However, ranking of regions for maturity differed between seasons. The latest sorghums recorded during the rainy season (FLK $=190$ days) were among the material from Gezira-Gedarif, and not in Equatoria where the latest landraces recorded during the postrainy season (FLR $=106$ days) were found. Furthermore, among regions, Gezira-Gedarif showed the smallest $(\mathrm{Pr}=0.27)$ correlation coefficient between FLR and FLK. Comparison of mean values among regions for both seasons showed that sorghums from
Equatoria were the tallest and latest in flowering whereas landraces from Gezira-Gedarif were the shortest and the earliest.

Panicle characteristics: Sorghums from Equatoria had good PEX, as the poorest exsertion recorded was nine centimeters. Pairwise mean comparison indicated that landraces from Equatoria were significantly more exserted than accessions from all other regions except Gezira-Gedarif. The highest values for PLG and PWD were found among sorghums from Kassala region $(\mathrm{PLG}=44 \mathrm{~cm}$ and $\mathrm{PWD}=25 \mathrm{~cm})$. Sorghum from Blue Nile tended to include mostly accessions with long and large panicles as they showed the greatest lower limits of range values for these two traits $\left(\mathrm{PLG}_{\min }=15 \mathrm{~cm}\right.$ and $\left.\mathrm{PWD}_{\text {min }}=6 \mathrm{~cm}\right)$. The 
opposite was true for sorghums from Equatoria, which had the lowest upper limit of range values for both panicle length and width $\left(\mathrm{PLG}_{\max }=32 \mathrm{~cm}\right.$ and $\mathrm{PWD}_{\max }=12 \mathrm{~cm}$ ). Based on comparison of means, sorghums from Kassala and Blue Nile regions appeared to possess long panicles that were larger than those found among landraces from Gezira-Gedarif, Upper Nile, and Equatoria.

Kernel characteristics: Sorghums originating from Kassala had both the smallest $(1.8 \mathrm{~mm})$ and the largest $(5 \mathrm{~mm}) \mathrm{KRS}$, as well as the highest $(7.3 \mathrm{~g})$ SWT. Gezira-Gedarif appeared as the region for sorghums with the smallest SWT (1.32 g). Sorghums that originated from Equatoria showed both the highest value for the lower limit $\left(\mathrm{KRS}_{\min }=2.5 \mathrm{~mm}\right)$ and the lowest value for the upper limit $\left(\mathrm{KRS}_{\max }=3 \mathrm{~mm}\right)$ of kernel size, indicating a reduced variability. Among all regions, landraces from Equatoria were characterized with the smallest mean values for both KRS and SWT.

\section{Qualitative characters}

Basal and nodal tillers: Among sorghums originating from Kassala and Blue Nile regions, only landraces with multiple BT were observed. Agronomic evaluation for presence or absence of NT showed that globally Sudanese landraces have a great $(92 \%)$ tendency to produce nodal tillers. The proportion was reversed in the collection from Equatoria where landraces were characterized with higher frequency of absence of nodal tillers and the lowest the proportion of accessions without tillers.

Plant, glume and midrib color: Most entries (93\%) in the Sudan collection had pigmented plants, with no significant differences among regions for the trait. Approximately one-half (53\%) of the collection contained dark (black/purple) glumes evenly distributed among regions. Frequency of red GLC among landraces from Gezira-Gedarif was significantly smaller (11\%) than in the rest of the collection. The proportion of accessions with sienna GLC was low (6\%) among landraces from the Upper Nile and higher among collections from Blue Nile (37\%), Kassala (33\%) and Gezira-Gedarif (24\%). The proportion of mahogany GLC was smaller (3\%) among sorghums originating from Blue Nile than in the rest of the collection and higher $(20 \%)$ in accessions from the Upper region. MIC for the entire Sudan collection was divided between white and dull colors representing $62 \%$ and $36 \%$ of the collection, respectively. This ratio was almost reversed for sorghums from Blue Nile with $34 \%$ white and $62 \%$ dull midrib accessions, whereas landraces form Gezira-Gedarif were more frequently $(66 \%)$ characterized with white MIC than the rest of the collection. Yellow midribs were rare in the Sudan collection, since only a small portion $(2 \%)$ of the landraces in the total collection had yellow midrib, and sorghums from Gezira-Gedarif had an even smaller $(0.3 \%)$ frequency of yellow midrib types.

Panicle characteristics: for PCS, a higher proportion $(56 \%)$ of accessions of the entire collection were characterized with compact panicles. Frequency of compact panicles was significantly higher among sorghums from Gezira-Gedarif and from Upper Nile (69\% for each). In the total collection, sorghums with loose panicles included $40 \%$ with stiff branches and $3 \%$ with drooping branches. Gezira-Gedarif sorghums were less commonly characterized with loose panicles, $31 \%$ showed loose and stiff branches and $1 \%$ loose and drooping branches. Sorghums from Upper Nile had a significantly lower frequency (17\%) of landraces with loose stiff branches and a relatively higher frequency (14\%) of landraces with loose drooping branches. Most of the Sudan collection $(68 \%)$ was classified as panicles with easy THR. The proportion of easily threshable panicles was higher among sorghums originating from Blue Nile (97\%), and smaller among landraces from Gezira-Gedarif (62\%) and Upper Nile (26\%) when each is compared to the rest of the collection. Partly threshable sorghums were significantly higher $(72 \%)$ in collection from Upper Nile, and significantly smaller (2\%) for accessions from Kassala. Among sorghums from Kassala, 20\% were recorded as difficult to thresh in contrast to the rest of the collection.

Glume coverage: Assessment of COV resulted in $48 \%$ of the entries in the collection characterized with only up to $1 / 4$ of the seed covered by the glume, $40 \%$ of the collection with $1 / 2$ of kernel covered by glume, and $12 \%$ of the collection with kernels $3 / 4$ to fully covered by glume. Sorghums from Gezira-Gedarif had an almost equal frequency of poorly covered kernels (42\%) and those with intermediate coverage (47\%). In both Blue Nile and Upper Nile regions, the landraces were characterized with poorly covered seeds, $70 \%$ and $60 \%$, respectively. These regions also have significantly less sorghum with $3 / 4$ to full coverage, about 3\% for both regions.

Kernel color: KRC was characterized as physical appearance of the kernels, notwithstanding the genetic 
basis for the expression of this trait. Approximately $55 \%$ of the collection was evenly distributed between sorghums with brown seeds and those with grey seeds. This distribution was different among landraces form Gezira-Gedarif where frequency of brown and grey were significantly lower (both $21 \%$ ), among landraces from Equatoria, which showed a higher frequency $(56 \%)$ of brown seeded sorghums, and among sorghums from Upper Nile where proportion of grey seeded plants was higher $(35 \%)$. Kernel color found in the collection was evenly distributed with straw $(15 \%)$, red $(13 \%)$, white $(11 \%)$, and yellow $(5 \%)$ kernels. Frequency of straw $(21 \%)$, white $(17 \%)$ and yellow (7\%) seeded landraces was higher in Gezira-Gedarif sorghums, and frequency of landraces with white kernels was the highest $(25 \%)$ in Blue Nile and the lowest (3\%) in the Upper Nile. Proportion of landraces with red kernels among sorghums from Blue Nile was lower $(4 \%)$ than in the rest of the collection.

Endosperm characteristics: TEX was significantly different among sorghums from different regions. Few landraces $(6 \%)$ in the Sudan collection possessed corneous endosperm. A higher proportion of landraces had kernels with either partly corneous $(40 \%)$ or partly to completely starchy $(54 \%)$ endosperm. Sorghums from Gezira-Gedarif showed an increased (9\%) frequency of landraces with mostly corneous endosperm and a reduced (45\%) frequency of partly starchy. Sorghums from Upper Nile showed reduced frequency of partly corneous endosperm (28\%) and increased frequency of partly to completely starchy endosperm (67\%). The presence or absence of SC showed a distribution in the Sudan collection of $60 \%$ with and $40 \%$ without subcoat. This ratio was different for accessions collected from Gezira-Gedarif, the only region where frequency of landraces with subcoat was lower than without subcoat (42\% vs. $58 \%$ ). In contrast, landraces from Upper Nile predominantly included kernels with subcoat $(74 \%)$.

\section{Estimates of diversity}

Phenotypic diversity was estimated by using multivariate analyses of several morphological characters. A principal component analysis involving all nine quantitative characters was performed where factors were retained when their eigenvalue exceeded the value of one. The first three axes explained $67 \%$ of the observed phenotypic diversity among landraces from the Sudan (Table 5). The first axis accounted for $36 \%$ of the variance and was significantly and positively associated with plant height and days to flowering recorded during both the rainy and post-rainy seasons. The second axis explained $19 \%$ of the variance and was associated with kernel size and 100-seed weight. A third axis, explaining $12 \%$ of the variance was associated with panicle length. Plotting the accessions on the first two axes (Figure 1) as well as on the first and third factor (not shown) graphically demonstrated that landraces from different regions cover the factorial space unequally. For instance, sorghums from Gezira-Gedarif, despite covering the greatest area, were more densely represented on the factorial space corresponding only to the shortest and earliest plants. Accessions from Upper Nile, widely and evenly distributed on the first axis, had more landraces represented in the factorial space where large and heavy seeded sorghums were plotted. Sorghums from Blue Nile were more broadly distributed among the tall and late landraces and also showed a more compact distribution among the short and early plants with small and light kernels. Similar observation could be made for sorghums from Kassala, where short and early landraces were essentially small-seeded. Landraces from Equatoria showed essentially sorghums with small-seeded, tall and among the latest plants.

Diversity was also estimated using the ShannonWeaver diversity index calculated from frequency distribution of multiple morphological traits (Table

Table 5. Eigenvalue and scores of the three first factors retained from the principal component analysis performed on the total Sudanese landrace collection and for nine quantitative characters (Varimax procedure).

\begin{tabular}{llll}
\hline & Factor 1 & Factor 2 & Factor 3 \\
\hline $\begin{array}{l}\text { Eigenvalue } \\
\text { Character }\end{array}$ & 3.20 & 1.73 & 1.09 \\
PHTR & & & \\
FLR & 0.77 & 0.03 & 0.37 \\
PHTK & 0.79 & 0.20 & 0.09 \\
FLK & 0.75 & -0.28 & 0.19 \\
PEX & 0.89 & 0.04 & 0.05 \\
PLG & 0.06 & 0.05 & 0.58 \\
PWD & 0.10 & -0.12 & 0.84 \\
KRS & 0.31 & -0.12 & 0.66 \\
SWT & 0.00 & 0.87 & -0.19 \\
Explained Variance & 0.04 & 0.86 & 0.07 \\
\hline
\end{tabular}

PHTR: plant height recorded during the Rabi season, FLR: days to flowering recorded during the Rabi season, PHTK: plant height recorded during the Kharif season, FLK: days to flowering recorded during the Kharif season, PEX: panicle exsertion, PLG: panicle length, PWD: panicle width, KRS: kernel size, SWT: 100-seed weight. 

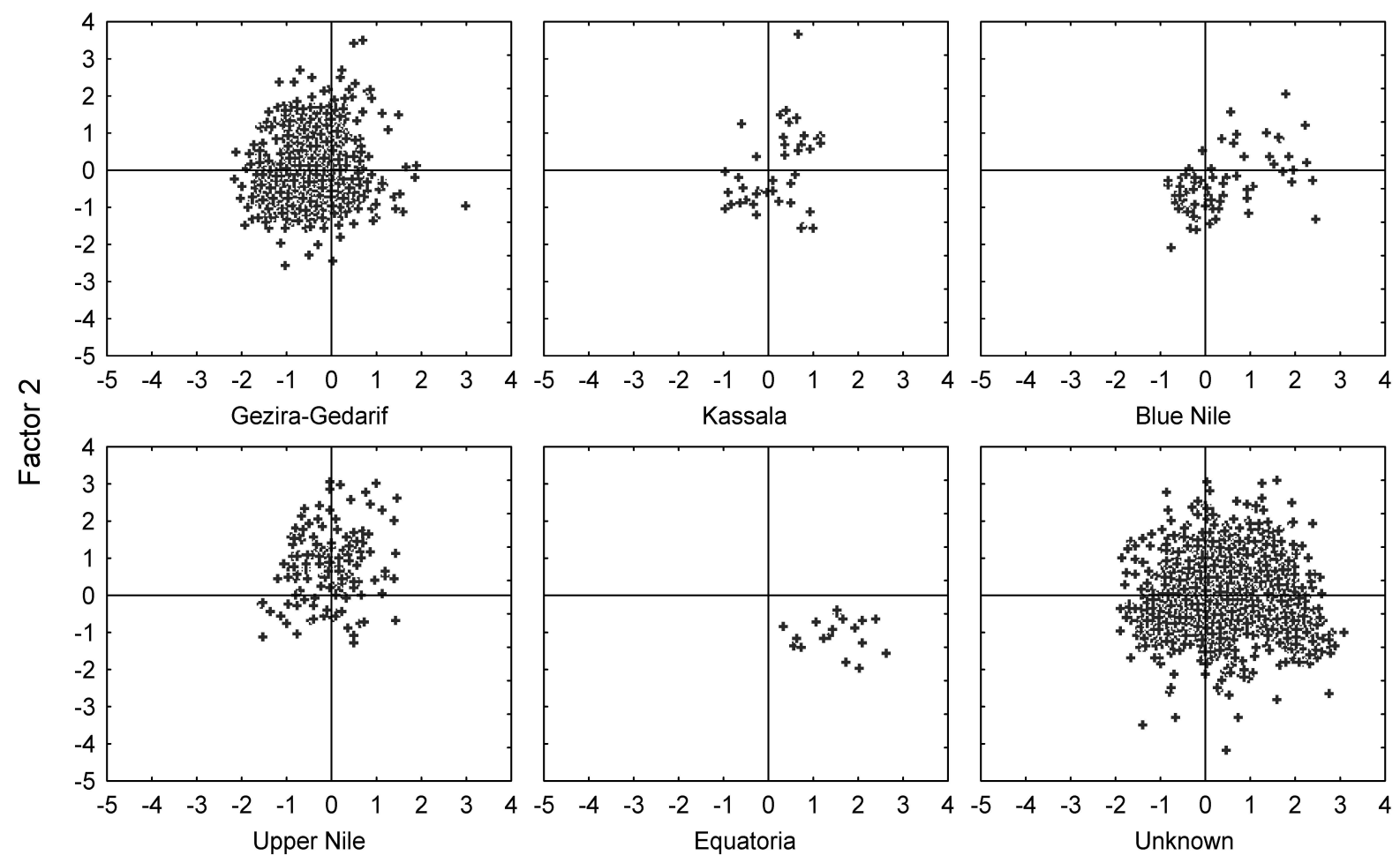

Factor 1

Figure 1. Principal component analysis on the total Sudanese landrace collection and for nine quantitative morpho-agronomic characters. Graphical representation of phenotypic diversity in the dimensional space as defined from the two first extracted factors (Varimax procedure). Separated scatterplots for each region and for the unknown source of landraces.

6). Estimates were based on phenotypic variability of the landraces, only considering the discrete characters. High global index of diversity $\left(\mathrm{H}^{\prime}=0.81\right)$ was found in the total collection. Within region, however, the range of mean index of diversity varied from $\mathrm{H}^{\prime}=$ 0.64 for accessions from Equatoria, to $\mathrm{H}^{\prime}=0.78$ for sorghums from Gezira-Gedarif. Pair-wise comparison of the diversity indices using the $t$ - test did not reveal significant differences $(\mathrm{p}<0.005)$ between the mean diversity indices obtained among the regions. However, the diversity indices differed among regions for specific characters. For instance, collections from Gezira-Gedarif (0.93) and Upper Nile (0.91) exhibited significantly higher diversity value for BT than Kassala and Blue Nile regions (both 0.53). For NT, Upper Nile showed the highest diversity value (0.44), while sorghums from Kassala were monomorphic. Equivalent diversity was found among regions for PIG except for Kassala and Equatoria where landraces were monomorphic. Landraces from Kassala exhibited more diversity (1.02) for MIC than landraces from Gezira-Gedarif (0.66) and Upper Nile
(0.7). For PCS, accessions from Equatoria (1.04) were more diverse than those from Gezira-Gedarif (0.65). THR and COV characters opposed the most diverse collections from both Gezira-Gedarif and Kassala, to collections from Blue Nile and Equatoria. Considering KRS, landraces from Gezira-Gedarif (1.73) were more diverse than those originating from Upper Nile (1.5).

\section{Discussion}

The Central Clay Plain of the Sudan is home to a great variety of sorghum types. With favorable rainfall distribution, heavy alluvial soils, and high seasonal temperatures, the area has a long history of sorghum cultivation, and currently presents a well developed irrigated and mechanized farming schemes (FAO, 2001). A number of agronomically elite landraces have been collected from this region (Ejeta 1982). Taxonomically, sorghums of the race Caudatum make up the most dominant type in Central Sudan and 
Table 6. Shannon-Weaver Diversity Indices $\left(\mathrm{H}^{\prime}\right)$, mean and standard error $( \pm$ S.E.) of landraces in each region based on 11 discrete characters.

\begin{tabular}{|c|c|c|c|c|c|c|}
\hline Characters & Gezira-Gedarif & Kassala & Blue Nile & Upper Nile & Equatoria & Total* \\
\hline BT & $0.93^{\mathrm{a}}$ & $0.53^{b}$ & $0.53^{\mathrm{b}}$ & $0.91^{\mathrm{a}}$ & $0.87^{\mathrm{ab}}$ & 1.08 \\
\hline NT & $0.20^{\mathrm{a}}$ & 0 & $0.07^{\mathrm{ab}}$ & $0.44^{\mathrm{c}}$ & $0.35^{\mathrm{abc}}$ & 0.27 \\
\hline PIG & $0.22^{\mathrm{a}}$ & 0 & $0.32^{\mathrm{a}}$ & $0.30^{\mathrm{a}}$ & 0 & 0.25 \\
\hline GLC & $1.19^{\mathrm{a}}$ & $1.29^{\mathrm{a}}$ & $1.15^{\mathrm{a}}$ & $1.07^{\mathrm{a}}$ & $1.01^{\mathrm{a}}$ & 1.20 \\
\hline MIC & $0.66^{\mathrm{a}}$ & $1.02^{\mathrm{b}}$ & $0.80^{\mathrm{ab}}$ & $0.70^{\mathrm{a}}$ & $0.85^{\mathrm{ab}}$ & 0.73 \\
\hline PCS & $0.65^{\mathrm{a}}$ & $0.76^{\mathrm{ab}}$ & $0.73^{\mathrm{ab}}$ & $0.83^{\mathrm{ab}}$ & $1.04^{\mathrm{b}}$ & 0.80 \\
\hline THR & $0.76^{\mathrm{a}}$ & $0.60^{\mathrm{a}}$ & $0.13^{\mathrm{b}}$ & $0.66^{\mathrm{a}}$ & 0 & 0.78 \\
\hline $\mathrm{COV}$ & $0.96^{\mathrm{a}}$ & $1.05^{\mathrm{a}}$ & $0.70^{\mathrm{b}}$ & $0.77^{\mathrm{b}}$ & $0.67^{\mathrm{b}}$ & 0.98 \\
\hline KRC & $1.73^{\mathrm{a}}$ & $1.61^{\mathrm{ab}}$ & $1.57^{\mathrm{ab}}$ & $1.50^{\mathrm{b}}$ & $1.23^{\mathrm{ab}}$ & 1.66 \\
\hline TEX & $0.57^{\mathrm{a}}$ & $0.50^{\mathrm{a}}$ & $0.47^{\mathrm{a}}$ & $0.49^{\mathrm{a}}$ & $0.36^{\mathrm{a}}$ & 0.54 \\
\hline $\mathrm{SC}$ & $0.68^{\mathrm{a}}$ & $0.69^{\mathrm{a}}$ & $0.68^{\mathrm{a}}$ & $0.58^{\mathrm{a}}$ & $0.67^{\mathrm{a}}$ & 0.67 \\
\hline Means & 0.78 & 0.73 & 0.65 & 0.75 & 0.64 & 0.81 \\
\hline \pm S.E. & 0.13 & 0.15 & 0.13 & 0.10 & 0.12 & 0.12 \\
\hline
\end{tabular}

BT: number of basal tillers, NT: nodal tillers, PIG: plant pigmentation, GLC: glume color, MIC: midrib color, PCS: panicle compactness and shape, THR: threshability, COV: glume covering, KRC: kernel color, TEX: endosperm texture, SC: subcoat. Unequal variance $t$-tests with Bonferroni adjustment; means in a row followed by the same letter are not significantly different at $\mathrm{p}<0.005$ (comparison-wise Type I error rate). * includes the unknown sources.

adjacent regions (de Wet and Harlan 1971) suggesting perhaps that Sudan was the center of origin for sorghums of the Caudatum race (Stemler et al. 1975). Other studies have described Caudatum as a race with great agronomic value (Doggett 1988), better adaptation to harsh conditions (Stemler et al. 1975) and a wide range of response to changes in photoperiod (Grenier 2000). This may explain the great contribution that sorghums from Sudan have made to global sorghum improvement efforts.

Distribution of racial types and overall phenotypic diversity among sorghum landraces in the Sudan is uneven. This suggests that selection and differentiation of types took place along a geographical pattern perhaps associated with climate and use (Doggett 1988; Asante 1995). This was corroborated through our principal component analysis that showed global phenotypic diversity in the Sudan collection as being differentially distributed among regions, with specific patterns drawn for each geographical area of origin. Assessment of the Shannon-Weaver index also showed sensitivity to both the number of descriptor classes and the distribution within phenotypic classes in each region. Among regions, the mean values for the Shannon-Weaver index are not significantly different, but differences were found when individual characters were considered. These observations suggest that some regions have high diversity for particular traits while in other regions selective pressures have reduced the variation to certain ideotypes.

The Shannon-Weaver index, based on both the species richness and the evenness of the distribution, is one of the most widely used diversity indices (Magurran 1988). This index is a relevant estimate commonly used for population ecology and measurement of species diversity (Pielou 1966; Jain et al. 1975). It is also popular especially in investigations of structural diversity (Magurran 1988). Besides, Shannon-Weaver diversity index is frequently used to estimate diversity from phenotypic descriptors among germplasm collections (Singh et al. 1998; Ayana and Bekele 1999; Balakrishnan et al. 2000; Grenier et al. 2000; Kefyalew et al. 2000; Dong et al. 2001; Grenier et al. 2001; Pecetti and Piano 2002) as well as for assessing molecular diversity (Paul et al. 1997; Rajora, et al., 1999; Kaundun et al. 2000; Lacerda et al. 2001; Larson et al. 2001). Furthermore, this index presents several useful properties, such as the additive properties that allow pooling of multivariate classes and likewise pooling over geographic regions, to evaluate the diversity component through hierarchical analyses of variance (Jain et al. 1975; Tolbert et al. 1978; Bogyo et al. 1980; Weltzien 1989; Perry and McIntosh 1991; Polignano et al. 1999; Kefyalew et al. 2000). In our study, Shannon-Weaver diversity index values for the Sudanese sorghum appear smaller than those found for the germplasm from Ethiopia (Ayana and Bekele 1998). However, neither the phenotypic descriptors nor the number of classes used to describe these two studies were the same. Therefore, careful attention should be given in the definition and aggregation of the phenotypic classes within a character since a distribution that approximates evenness, i.e., where each class tends to have the same observed 
frequency, could result in an overestimated diversity index and vice versa.

Understanding the diversity of germplasm collections in major repositories is crucial to effective exploitation of crop genetic resources. Centers of diversity such as northeast Africa are precious environments. From a conservation point of view, expectations about the way in which genetic diversity within a species is distributed among its populations needs to be taken into consideration (Gray 1996). In some areas of the Sudan, cultivated sorghums often grow in sympatry with weedy and wild-related species, which presents great benefit for gene diffusion from wild and weedy forms on to related cultivated crops. Such is precisely the case in the Central Clay Plains, where along the main road from Khartoum to Gedarif and onwards to Kassala, one observes the progression of wild types, shattercanes, and cultivated forms when moving from the main highways to farmlands. Further analysis of genetic diversity on sorghums of the Sudan, including wild, weedy, intermediate, and cultivated types, would permit better understanding of gene flow and evolutionary relationships among related gene pools and may result in improved use and conservation of sorghum genetic resources.

\section{Acknowledgements}

The authors would like to express many thanks to J. Santini for her valuable comments and help provided for the statistical considerations. This work was partially supported by USAID Grant No. LAG-G-00-9690009-00 through INTSORMIL, the International Sorghum and Millet CRSP. Journal Paper No. 17063 of the Agricultural Research Program, Purdue University.

\section{References}

Appa Rao S., Prasada Rao K.E., Mengesha M.H. and Reddy G.V. 1996. Morphological diversity in sorghum germplasm from India. Genet. Resour. Crop Evol. 43: 559-567.

Asante S.A. 1995. Sorghum quality and utilization. African Crop Sci. Journal 3: 231-240.

Ayana A. and Bekele E. 1998. Geographical patterns of morphological variation in sorghum (Sorghum bicolor (L.) Moench) germplasm from Ethiopia and Eritrea: qualitative characters. Hereditas 129: 195-205.

Ayana A. and Bekele E. 1999. Multivariate analysis of morphological variation in sorghum (Sorghum bicolor (L.) Moench) germ- plasm from Ethiopia and Eritrea. Genet. Resour. Crop Evol. 46: $273-284$.

Ayana A. and Bekele E. 2000. Geographical patterns of morphological variation in sorghum (Sorghum bicolor (L.) Moench) germplasm from Ethiopia and Eritrea: Quantitative characters. Euphytica 115: 91-104.

Bacon S.H. 1948. Crops of Sudan. In: Tot Hill J.D. (ed.), Agriculture in the Sudan. Oxford Univ. Press, pp. 302-400.

Balakrishnan R., Nair N.V. and Sreenivasan T.V. 2000. A method for establishing a core collection of Saccharum officinarum L. germplasm based on quantitative-morphological data. Genet. Resour. Crop Evol. 47: 1-9.

Bogyo T.P., Porceddu E. and Perrino P. 1980. Analysis of sampling strategies for collecting genetic material. Econ. Botany 34: 160174.

de Wet J.M.J. and Harlan J.R. 1971. The origin and domestication of Sorghum bicolor. Econ. Botany 25: 128-135.

Doggett H. 1988. Sorghum. 2nd edn. Longman Scientific \& Technical, UK, copublished in the United States with John Wiley \& Sons, Inc., New York.

Dong Y.S., Zhuang B.C., Zhao L.M., Sun H. and He M.Y. 2001. The genetic diversity of annual wild soybeans grown in China. Theor. Appl. Genet. 103: 98-103.

Ejeta G. 1980. Status of sorghum improvement research in the Sudan. ICRISAT, West African Cooperative Program, Wad Medani, Sudan.

Ejeta G. 1982. Annual report. ICRISAT-Sudan.

FAO, 2001. Special Report FAO/WFP crop and food supply assessment mission to Sudan. 22 December 2000. http: // fao.org.

Gray A.J. 1996. The genetic basis of conservation biology. In: Spellerberg I.F. (ed.), Conservation biology. Longan, Singapore, pp. $107-121$.

Grenier C., Bramel-Cox P.J., Noirot M., Prasada Rao K.E. and Hamon P. 2000. Assessment of genetic diversity in three subsets constituted from the ICRISAT sorghum collection using random vs. non-random sampling procedures. A. Using morpho-agronomical and passport data. Theor. Appl. Genet. 101: 190-196.

Grenier C., Hamon P. and Bramel-Cox P.J. 2001. Core collection of sorghum: II. Comparison of three random sampling strategies. Crop Sci. 41: 241-246.

Grenier C. 2000. Diversité génétique des sorghos cultivés-Gestion des ressources génétiques et contribution des marqueurs moléculaires à la constitution de core collections, Doctorat, Université de Montpellier II.

Harlan J.R. and de Wet J.M.J. 1972. A simplified classification of cultivated sorghum. Crop Sci. 12: 172-176.

Harlan J.R. and Stemler A. 1976. The races of sorghum in Africa. In: Harlan J.R., de Wet J.M.J. and Stemler A.B.L. (eds), Origins of African Plant Domestication. Mouton publishers, The HagueParis, pp. 465-478.

Hutcheson K. 1970. A test for comparing diversities based on the Shannon formula. J. Theor. Biol. 29: 151-154.

Jain S.K., Qualset C.O., Bhatt G.M. and Wu K.K. 1975. Geographical patterns of phenotypic diversity on a world collection of durum wheats. Crop Sci. 15: 700-704.

Johnson D.H. 1995. Statistical sirens: the allure of nonparametrics. Ecology 76: 1998-2000.

Kaundun S.S., Zhyvoloup A. and Park Y.-G. 2000. Evaluation of the genetic diversity among elite tea (Camellia sinensis var. sinensis) accessions using RAPD markers. Euphytica 115: 7-16.

Kefyalew T., Tefera H., Assefa K. and Ayele M. 2000. Phentoypic 
diversity for qualitative and phenologic characters in germplasm collections of tef (Eragrostis tef). Genet. Resour. Crop Evol. 47: $73-80$.

Lacerda D.R., Acedo M.D.P., Filho J.P. and Lovato M.B. 2001. Genetic diversity and structure of natural populations of Plathymenia reticulata (Mimosoideae), a tropical tree from the Brazilian Cerrado. Mol. Ecol. 10: 1143-1152.

Larson S.R., Cartier E., Mccracken C.L. and Dyer D. 2001. Mode of reproduction and amplified fragment length polymorphism variation in purple needlegrass (Nassella pulchra) utilization of natural germplasm sources. Mol. Ecol. 10: 1165-1177.

Li Y. and Li C. 1997. Phenotypic diversity of sorghum landraces in China International Conference on Genetic Improvement of Sorghum and Pearl Millet, pp. 659-668.

Magurran A.E. 1988. Ecological diversity and its measurement. Princeton University Press, New Jersey.

Mann J.A., Kimber C.T. and Miller F.R. 1983. The origin and early cultivation of sorghum in Africa. Texas Agricultural Experiment Station Bulletin B-1454.

Paul S., Wachira F.N., Powell W. and Waugh R. 1997. Diversity and genetic differentiation among populations of Indian and Kenyan tea (Camellia sinensis (L.) O. Kuntze) revealed by AFLP markers. Theor. Appl. Genet. 94: 255-263.

Pecetti L. and Piano E. 2002. Variation of morphological and adaptative traits in subterranean clover populations from Sardinia (Italy). Genet. Resour. Crop Evol. 49: 189-197.

Perry M.C. and McIntosh M.S. 1991. Geographical patterns of variation in the USDA soybean collection: I. Morphological traits. Crop Sci. 31: 1350-1355.

Pielou E.C. 1966. Shannon's formula as a measure of specific diversity: Its use and misuse. Am. Nat. 100: 463-465.

Polignano G.B., Alba E., Uggenti P. and Scippa G. 1999. Geographical patterns of variation in Bari faba bean germplasm collection. Genet. Resour. Crop Evol. 46: 183-192.
Rajora O.P. 1999. Genetic biodiversity impacts of silvicultural practices and phenotypic selection in white spruce. Theor. Appl. Genet. 99: 954-961.

Rajora, et al., 1999.

Rao N.G.P. 1977. Sorghum research and production in Sudan, Somalia, Yemen Arab Republic and people's democratic republic of Yemen. FAO, Near East Regional Office, Cairo.

Rao K.P. and Mengesha M.H. 1980. Sorghum and millets germplasm collection in eastern Sudan. Genetic Resources-16. ICRISAT, Patancheru, India.

Rao N.K. and Bramel P.J. 2000. Manual of Genebank operations and procedures. Technical manual no. 6. ICRISAT, Patancheru, India.

Rosenow D.T. and Dahlberg J.A. 2000. Collection, conservation and utilization of sorghum. In: Smith C.W. and Frederiksen R.A. (eds), Sorghum: Origin, History, Technology, and Production. John Wiley \& Sons, Inc., pp. 309-328.

SAS Institute Inc., 2001. SAS/STAT software SAS language guide for personal computers. Edition 8.02. SAS Institute Inc., Cary, NC.

Singh K.B., Ocampo B. and Robertson L.D. 1998. Diversity for abiotic and biotic stress resistance in the wild annual Cicer species. Genet. Resour. Crop Evol. 45: 9-17.

Snedecor G.W. and Cochran W.G. 1989. Statistical methods. Iowa State University Press, Ames.

Statsoft 1997. Statistica for Windows. StatSoft, Tulsa, OK, USA

Stemler A.B.L., Harlan J.R. and de Wet J.M.J. 1975. Evolutionary history of cultivated sorghums (Sorghum bicolor [L.] Moench) of Ethiopia. Bull. Torrey Bot. Club 102: 325-333.

Tolbert D.M., Qualset C.O., Jain S.K. and Craddock J.C. 1978. A diversity analysis of a world collection of barley. Crop Sci. 19: 789-794.

Weltzien E. 1989. Differentiation among barley landrace populations from the Near East. Euphytica 43: 29-39. 